\title{
A formação da economia cafeeira do vale do Paraíba
}

\author{
Marco Aurélio dos Santos \\ Breno Aparecido Servidone Moreno**
}

Fragoso, João. Barōes do café e sistema agrário escravista: Paraíba do Sul, Rio de Janeiro (1830-1888). Rio de Janeiro: 7Letras, 2013.

Nos últimos anos, as pesquisas feitas nas áreas de História Social e História Econômica vêm deslindando a complexa realidade econômica, política e social de diversas localidades brasileiras. Historiadores com diferentes abordagens, favorecidos por uma ampliação do conjunto documental acessível à pesquisa, estão conseguindo descortinar a significativa complexidade brasileira. O livro Barōes do café e sistema agrário escravista: Paraíba do Sul, Rio de Janeiro (1830-1888), do historiador João Fragoso, insere-se nesse amplo corpus bibliográfico que vem, a cada ano que passa, enriquecendo a compreensão de diversos municípios do país. Em linhas gerais, Barôes do café é uma versão resumida dos capítulos de história agrária de sua tese de doutorado, defendida em $1990,{ }^{1}$ e pro-

${ }^{1}$ FRAGOSO, João L. R. Comerciantes, fazendeiros e formas de acumulação em uma economia escravista-exportadora no Rio de Janeiro: 1790-1888. Tese cura investigar a estrutura e a hierarquia no sistema agrário escravista-exportador, bem como a reprodução desse sistema no município de Paraíba do Sul, situado no médio Vale do Paraíba fluminense.

João Fragoso inicia o capítulo 1, "Estrutura e hierarquia no sistema agrário escravista-exportador", lançando um conceito-chave: o de "recriação de sistemas agrários escravistas". Segundo seu ponto de vista, esse conceito apresenta três significados. A citação, apesar de longa, merece ser reproduzida na íntegra, pois mostra o que pode ser considerado como sendo a tese central do autor. Sendo assim, "a noção de recriação de sistemas agrários escravistas [...]”

- diz respeito à continuidade de uma sociedade não capitalista, onde (sic) as relações sociais de produção identificamse com relações sociais de subordinação, os fatores de produçáo (inclusive a mão de obra) se apresentam enquanto mercadorias e se verifica a hegemonia do capital mercantil (fenômeno que se traduz na preponderância

(Doutorado em História Social) — PPHS-UFF, Rio de Janeiro, 1990.

DOI - http://dx.doi.org/10.1590/2237-101X0183409

* Doutor em História Social pela FFLCH-USP, Universidade de São Paulo - São Paulo, SP, Brasil. E-mail: marcoholtz@uol.com.br.

** Centro de Estudos Migratórios - São Paulo, SP, Brasil. Mestre e doutorando em História Social pela FFLCH-USP. E-mail: berenomor@yahoo.com.br. 
da elite de comerciantes de grosso trato sobre a hierarquia econômica colonial);

- essa recriação gera demanda para as produçóes voltadas para o mercado interno e, com isso, permite a recorrência da formação econômico-social escravistacolonial;

- e, por último, tal movimento reitera, na fronteira, os traços gerais da sociedade escravista: a produção de mercadorias, uma hierarquia econômico-social diferenciada e a hegemonia do capital mercantil. (p. 43)

Um pouco adiante, Fragoso escreve que, nessa economia de Paraíba do Sul,

as relaçôes de produção se confundem com as de poder, ou melhor, cuja forma de extorsão do sobretrabalho depende de elementos extraeconômicos: o trabalhador direto é homem de outro homem. Entretanto, esse fato não causa o desvio do excedente da economia. Ao contrário de outras sociedades pré-capitalistas, a recorrência das relaçóes de poder (e, com elas, as de produção) está presa aqui ao retorno do sobretrabalho para a produção por meio dos senhores de homens. (p. 43-44)

Essa sociedade, porém, tem especificidades: "a reprodução ampliada adquire um sentido particular que tem como resultado a reiteração e o aumento do poder, sem que isso signifique que tal economia se fundamente numa lógica do lucro pelo lucro" (p. 44).

Como já foi dito, esse início de capítulo apresenta a base conceitual que dá suporte ao estudo sobre Paraíba do Sul. Nesse sentido, partindo do que Fragoso escreveu, é possível tirar as seguintes conclusóes sobre o "sistema agrário escravista-exportador": (a) esse é um sistema de agricultura mercantil-escravista; (b) o sistema baseia-se na monocultura, na agricultura extensiva e no baixo nível técnico; (c) existe a produção de lucro, com a ressalva já apontada; (d) o sistema agrário funciona numa sociedade pré-capitalista/ não capitalista (os dois conceitos são usados ao longo do trabalho); (e) fatores de produção como a mão de obra "se apresentam como mercadorias"; (f) o capital mercantil é hegemônico e, por fim (g) existe produção de mercadorias (café entre outras).

Uma primeira observação a ser feita é a de que o autor associa dois conceitos que são significativamente diferentes: o de "sociedade pré-capitalista" (p. 44) e o de "sociedade não capitalista" (p. 43). Fragoso usa diversas variantes desses dois conceitos. Algumas delas são: "estrutura econômica pré-capitalista" (p. 45), "agricultura pré-capitalista” (p. 57), "mercado pré-capitalista" (p. 57) e "mercado pré-industrial” (p. 58). Todas essas classificaçôes seriam características do "sistema agrário escravista-exportador".

Para Fragoso, Paraíba do Sul foi uma área de "agricultura pré-capitalista altamente especializada, cuja reprodução, tanto no que concerne à geração de suas rendas como o seu abastecimento, passa pelo mercado". Esse é mais um trecho que confirma que se trata, segundo o autor, de uma sociedade pré-capitalista produtora de mercadorias. Afinal, se as rendas e o abastecimento passam pelo mercado, então o que a sociedade produz são mercadorias para abastecer a fazenda e para garantir sua 
sobrevivência (reiteração/reprodução, como talvez preferisse escrever $\mathrm{o}$ autor).

Ora, em primeiro lugar deve-se salientar que a caracterização de Paraíba do Sul como uma sociedade pré-capitalista mostra um vínculo do autor com o trabalho de Eugene D. Genovese, The Political Economy of Slavery: Studies in the Economy and Society of the Slave South. ${ }^{2}$ Por outro lado, fica claro que muitas das caracterizaçôes feitas por Fragoso carecem de rigor conceitual. Deve-se sublinhar, de imediato, que existe uma diferença abissal entre os conceitos de "sociedade pré-capitalista" e "sociedade não capitalista". O prefixo "pré" significa anterioridade e um momento de transição entre uma sociedade, digamos, colonial, e outra capitalista. Já afirmar uma sociedade "não capitalista" significa conceber outro sistema ou modo de produçấo. Como o autor não conceitua essas expressôes, é impossível associar o conceito de "sociedade não capitalista" com o de "sociedade pré-capitalista" em Paraíba do Sul. O conceito "sociedade não capitalista" permite pensar que a "sociedade em estudo [no caso Paraíba do Sul] não é capitalista”. O adjunto adverbial de negação

\footnotetext{
${ }^{2}$ Um exemplo desse vínculo pode ser lido no seguinte trecho: "The planters were not mere capitalists; they were precapitalist, quasi-aristocratic landowners who had to adjust their economy and ways of thinking to a capitalist world market. Their society, in its spirit and fundamental direction, represented the antithesis of capitalism, however many compromises it had to make". GENOVESE, Eugene D. The Political Economy of Slavery: Studies in the Economy and Society of the Slave South. Middletown: Wesleyan University Press, 1989, p. 23. Para uma avaliação crítica da interpretação de Genovese, ver TOMICH, Dale W. Pelo prisma da escravidão: trabalho, capital e economia mundial. São Paulo: Edusp, 2011, p. 28-32.
}

"não" faz supor a existência de outro modo de produção. De qualquer modo, ao associar "sociedade não capitalista" e "sociedade pré-capitalista", tem-se uma confusão conceitual que dificulta a compreensão da agricultura cafeeiro-escravista de Paraíba do Sul. Essa falta de rigor conceitual marca a obra e chama facilmente a atenção do leitor. ${ }^{3}$

De modo geral, João Fragoso é pouco cuidadoso nos procedimentos metodológicos empregados em Baróes do café. O autor utilizou "mais de 400" inventários post mortem

${ }^{3} \mathrm{O}$ conceito de "sociedade pré-capitalista", com o prefixo "pré" compreendido como um momento de transição, está muito bem caracterizado no "Debate Brenner" e no debate sobre a transiçáo do feudalismo para o capitalismo. Não é objetivo desta resenha desenvolver essa questão do conceito de sociedade pré-capitalista. Contudo, vale a pena ler a definiçáo de R. H. Hilton para "pré-capitalista" em HILTON, R. H. Introduction. In: ASTON, T. H. \& PHILPIN C. H. E. The Brenner Debate: Agrarian Class Structure and Economic Development in Pre-Industrial Europe. Cambridge: Cambridge University Press, 1985, p. 5. Ver também a definição apresentada por Robert Brenner em BRENNER, Robert. The Origins of Capitalist Development: a Critique of Neo-Smithian Marxism. New Left Review, Londres, n. 104,1977 , p. 37. Mais ainda, vale a pena considerar a proximidade entre a "sociedade pré-capitalista de Paraíba do Sul”, conforme caracterização de Fragoso (ver especialmente os itens "c", "f" e "g" citados anteriormente), e o conceito usado por Paul M. Sweezy de "economia pré-capitalista de produção de mercadorias". Esse conceito foi usado por Sweezy para entender "o sistema que prevaleceu na Europa ocidental durante os séculos XV e XVI". Ver SWEEZY, Paul. O debate sobre a transição: uma crítica. In: SWEEZY, Paul et al. A transição do feudalismo para o capitalismo: um debate. Rio de Janeiro: Paz e Terra, 1977, p. 60-63. O artigo citado de Brenner é uma apreciação crítica da caracterização de Sweezy sobre o período de transiçáo e sobre uma sociedade que, segundo o entendimento do historiador norte-americano crítico de Maurice Dobb, não era nem feudal nem capitalista nos séculos XV e XVI. 
e 2.223 escrituras públicas de compra-venda e hipotecas entre os anos de 1830 e 1885 (p. 20). A partir dos inventários, os agentes coevos foram distribuídos em uma hierarquia econômica composta por três grandes grupos de fortunas (em libras esterlinas). Quanto ao corte cronológico, Fragoso não justifica a pertinência de dividi-lo em subperíodos (1830-1840; 1845-1850; 1855-1860; $1861-1865 ; 1870-1875 ; 1880-1885)$ e nem a razão pelo qual certos quinquênios foram excluídos da amostra. Da mesma forma, não apresenta o método de conversão do mil-réis em libras esterlinas. Por fim, não esclarece os motivos pelos quais não utilizou em todos os quadros, gráficos e tabelas que contemplam dados extraídos dos inventários, a totalidade de processos de sua amostra inicial (os 462 inventários, como se constata no Quadro 16, no capítulo 1). ${ }^{4}$ Por exemplo, o Quadro 3, na página 48, apresenta os "investimentos nas fazendas de café". Nesse quadro, o autor utiliza-se de 224 inventários, ou seja, cerca de $49 \%$ do total pesquisado. O mesmo número de inventários (224) se repete nos Quadros 14 e 15, às páginas $70 \mathrm{a} 72$.

Deve-se destacar que, em alguns casos, a amostra de inventários é táo pequena que pode até mesmo comprometer a validade das análises de João Fragoso. Um bom exemplo do que estamos apontando pode ser observado no Quadro 24 (p. 122), que exibe a origem dos créditos dos grupos de fortuna em Paraíba do Sul entre 1840 e 1880 . Nota-se que o autor utilizou pouquíssimos inven-

\footnotetext{
${ }^{4}$ Apenas na confecção do Quadro 16 (p. 78), que apresenta dados referentes à presença de fortunas no mercado de escrituras de Paraíba do Sul, Fragoso valeu-se de todos os inventários de sua amostragem.
}

tários (12 para o período 1840-1850, 33 para 1851-1871 e 10 entre 1871-1880) para determinar se o crédito era oriundo de Paraíba do Sul ou do Rio de Janeiro.

João Fragoso reconhece que a metodologia adotada em sua pesquisa tem "uma série de problemas" (p. 22). Contudo, malgrado essa observação, o autor acredita ter alcançado o objetivo proposto ao perceber as "mudanças de uma dada hierarquia social, e a vida de seus agentes, no tempo, e portanto em meio às flutuaçôes econômicas da sociedade" (p. 22). No entanto, seu livro não apresenta a dinâmica desse sistema na formação histórica do Brasil e não leva em conta os processos globais mais amplos da economia-mundo capitalista. Além disso, Fragoso afirma que o sistema agrário de Paraíba do Sul conserva "uma certa autonomia das flutuaçôes da economia escravista-colonial frente às conjunturas do mercado internacional" (p. 65). Ora, sabe-se que essa autonomia nunca existiu. Esse assunto é objeto de importante debate historiográfico pelo menos desde a publicação de $O$ arcaísmo como projeto. 5

\footnotetext{
${ }^{5}$ A tese segundo a qual a economia colonial brasileira gozava de "autonomia" frente à economia global já havia sido desenvolvida pelo autor em $O$ arcaísmo como projeto, redigido em parceria com Manolo Florentino. FRAGOSO, Joáo; FLORENTINO, Manolo. O arcaísmo como projeto. Mercado atlântico, sociedade agrária e elite mercantil em uma economia colonial tardia. Rio de Janeiro, c. 1790-c. 1840. 1. ed., 1993. Ed. rev. e ampl. Rio de Janeiro: Civilização Brasileira, 2001. Vale notar que esta tese também está presente em: FLORENTINO, Manolo. Em costas negras: uma história do tráfico de escravos entre a África e o Rio de Janeiro (séculos XVIII e XIX). 1. ed., 1997. Sáo Paulo: Companhia das Letras, 2010; SAMPAIO, Antonio Carlos Jucá de. Na encruzilhada do império: hierarquias sociais e
} 
Trabalhos recentes em inventários questionam outra tese presente em Homens de grossa aventura ${ }^{6}$ e n'O arcaísmo como projeto e reproduzida em Baróes do café. A noção segundo a qual a história do sistema agrário escravista é resultado de um processo global de reprodução que foi "originado de uma acumulação previamente realizada no comércio" (p. 43) é uma hipótese que pode servir para alguns casos específicos. Contudo, essa hipótese não deve ser generalizada para as demais regiôes do médio Vale do Paraíba, coração da cafeicultura escravista do Oitocentos. Em Bananal - e em outras localidades do

conjunturas econômicas no Rio de Janeiro (c. 1650c. 1750). Rio de Janeiro: Arquivo Nacional, 2003. Para um contraponto ver, entre outros, os seguintes estudos: MARQUESE, Rafael; TOMICH, Dale. O Vale do Paraíba escravista e a formação do mercado mundial do café no século XIX. In: SALLES, Ricardo; GRINBERG, Keila (Org.). O Brasil imperial (1808-1889). Volume II (1831-1871). Rio de Janeiro: Civilização Brasileira, 2009, p. 345-347. TOMICH, Dale. A "Segunda Escravidão". In:__. Pelo prisma da escravidão: trabalho, capital e economia mundial. São Paulo: Edusp, 2011, p. 81-97. MARQUESE, Rafael. As desventuras de um conceito: capitalismo histórico e a historiografia sobre a escravidão brasileira. Revista de História (USP), v. 169, p. 223-253, 2013. MARIUTTI, Eduardo; NOGUERÓL, Luiz Paulo; DANIELI NETO, Mário. Mercado interno colonial e grau de autonomia: crítica às propostas de João Luís Fragoso e Manolo Florentino. Estudos Econômicos: IPE-USP, São Paulo, v. 31, n. 2, p. 369-393, abr./jun. 2001. MORENO, Breno Aparecido Servidone. A formaçáo da cafeicultura em Bananal, 1790-1830. In: MUAZE, Mariana; SALLES, Ricardo (Org.). O Vale do Paraíba e o Império do Brasil nos quadros da Segunda Escravidão. Rio de Janeiro: 7Letras, 2015, p. 328-350.

${ }^{6}$ Cf. FRAGOSO, João. Homens de grossa aventura: acumulação e hierarquia na praça mercantil do Rio de Janeiro (1790-1830). Rio de Janeiro: Arquivo Nacional, 1992.
Vale do Paraíba paulista ${ }^{7}$ — a montagem da cafeicultura escravista obedeceu a outros mecanismos. A implantação e a disseminação da cultura cafeeira provocaram intensas mudanças na composição econômica dos domicílios. Os fogos que, em sua maioria, dedicavam-se à produção de mantimentos (milho, arroz, feijão e farinha de mandioca), sobretudo para a própria subsistência, no início do século XIX, logo se converteram em propriedades rurais voltadas à exportação de café para o mercado mundial. Os agricultores que não dispunham de capital para ingressar na cafeicultura adotaram a estratégia de cultivar milho e feijão entre as fileiras dos arbustos de café recém-plantados. Com isso, eles foram se deslocando paulatinamente da produção de gêneros para a atividade cafeeira, sem abdicar do cultivo de víveres para o autoconsumo. ${ }^{8}$

Por fim, cabe salientar que, apesar de questionar alguns procedimentos metodológicos utilizados para compor o livro Baróes

${ }^{7}$ Cf. MOTTA, José Flávio. Corpos escravos, vontades livres: estrutura da posse de cativos e família escrava em um núcleo cafeeiro (Bananal, 1801-1829). São Paulo: Annablume/Fapesp, 1999. LUNA, Francisco; KLEIN, Herbert. Evolução da sociedade e economia escravista de São Paulo, de 1750 a 1850. São Paulo: Edusp, 2005.

${ }^{8}$ Cf. MORENO, Breno Aparecido Servidone. A formação da cafeicultura em Bananal, 1790-1830, op. cit. Ver também o livro de Maria Luíza Marcílio, resultado de sua tese de livre-docência apresentada junto ao Departamento de História da Universidade de São Paulo em 1974. Nessa pesquisa, Marcílio procurou investigar como "a infraestrutura ou o suporte humano, material e social sobre o qual se instituiu a economia cafeeira teve formação anterior a ela e náo apenas concomitante". MARCÍLIO, Maria Luiza. Crescimento demográfico e evolução agrária paulista: 1700-1836. São Paulo: Hucitec/Edusp, 2000, p. 16. 
do café, Fragoso reproduz uma série de argu- riais e tentar compreender sua atuação no mentos de seus trabalhos anteriores, como contexto do desenvolvimento da economia a noção de "autonomia". Esses argumentos, cafeeiro-escravista do século XIX. Malgrajá amplamente debatidos pela historiografia, do as polêmicas em torno de suas teses, sua apontam para outra direção, diferente da empreitada fomenta o debate historiográfico sustentada pelo autor. De qualquer modo, e o conhecimento da formação econômica e cabe salientar o esforço de Fragoso em olhar do Estado nacional brasileiro no Oitocentos. para as elites e suas estratégias empresa- 